\title{
The 50 Most Highly Cited Reviews of 2013-2017
}

\author{
A. V. Bagirova ${ }^{a, *}$, D. V. Kosyakov ${ }^{a, * *}$, and A. E. Guskov ${ }^{a, * * *}$ \\ ${ }^{a}$ State Public Scientific Technological Library, Siberian Branch, Russian Academy of Sciences, Novosibirsk, Russia \\ *e-mail: Bagirova@spsl.nsc.ru \\ **e-mail:kosyakov@spsl.nsc.ru \\ ***e-mail:guskov@spsl.nsc.ru \\ Received April 21, 2021
}

\begin{abstract}
The main characteristics of the 50 most highly cited reviews based on Scopus data, published in 2013-2017, have been studied. A detailed analysis of these reviews is given in terms of topic relevance, authors' team authority, and sources rating. The majority of reviews were for medicine, chemistry, biochemistry, genetics, and molecular biology. Many of them were written with the participation of an authoritative expert group from the world's leading scientific institutions as a regularly updated result review. The largest numbers of authors belonged to the $\mathrm{G} 7$ countries, China, and Switzerland. In comparison with these reviews, the Russian practice of preparing review publications has been considered.
\end{abstract}

Keywords: reviews, citation, systematization of knowledge, scientific disciplines

DOI: $10.3103 /$ S0147688221030035

\section{INTRODUCTION}

Review publications play an important role in the research process, systematizing and summarizing the results obtained by different authors in different parts of the world. In the total flow of scientific publications, their share is approximately $4.5-6 \%$, ranging from $0.7 \%$ to $15.9 \%$ in different scientific disciplines [1]. The annual stream of review publications of more than 100000 articles is often an object of study in itself. Reviews are valued by researchers and often receive more citations than original articles [2]. There are various methods for preparing reviews and ways of writing them [3-6]. As an example, G. Paré et al. [7] proposed distinguishing between narrative reviews, descriptive reviews, reviews of reviews, meta-analysis, systematic, umbrella, theoretical, realistic, and critical reviews. Few argue that writing such reviews is research in itself.

Moreover, for a modern scientist, preparing survey materials is a key skill. This is necessary at the planning stage of a new study, when it is essential to take existing results into account, as well as during the preparation of scientific articles, because modern requirements for publications in leading scientific journals suggest that their introductory part should actually be a small overview on the research topic, and an article itself contains 40-50 links to other sources on average.

Soviet science had an extensive and rich practice in the systematization of scientific and technical information. Vivid examples are the existing institutes of scientific information such as the All-Russian Institute for Scientific and Technical Information (VINITI), Russian Academy of Sciences, and Institute of Scientific Information for Social Sciences (INION), Russian Academy of Sciences, as part of the State System of Scientific and Technical Information (SSSTI). However, in recent years, the preparation of scientific reviews has not been a priority task for Russian scientists. They took part in the preparation of only $1.5 \%$ (6951 out of 462 175) of the review publications in 2013-2017 (according to Scopus), although the share of all publications with Russian participation in this period was $2.39 \%$. A preliminary analysis showed that our compatriots are very rarely found as coauthors in highly cited reviews. Perhaps the question should be raised about the lag of the Russian scientific school in this important component. A likely negative consequence of this is a lower quality of research, which is less based on world experience, and the low authority of publications, expressed, among other things, in the total number of citations (according to this parameter, our country has been an outsider for a long time, for example, in the Scimago ranking).

To solve the problem of the quality of preparation of scientific reviews, the Russian Foundation for Basic Research in 2019-2020 held competitions for the provision of grants to finance the preparation and publication of scientific review articles. This was undoubtedly an important step, but it alone will not be enough. We believe that it is very important for Russian science that a critical mass of researchers comprehend the existing practices of preparing reviews in the world, 
which in various disciplines may have their own specifics, add them to their professional arsenal, and subsequently overcome the historically formed gap.

\section{THE LIST OF REVIEWS}

The purpose of this study was to identify scientific disciplines in which the systematization of scientific knowledge is most in demand, and to determine the characteristic properties inherent in highly cited reviews.

To solve this problem, we selected the 50 most highly cited reviews for the period from 2013 to 2017, according to Scopus. For this purpose, we used the search query "DOCTYPE(re) AND PUBYEAR BEF 2018 PUBYEAR AFT 2012." The period of 2013-2017 was chosen because we were interested in a relatively small time interval, which would contain reviews that are (a) relevant, (b) that managed to collect a sufficient number of citations, and (c) whose citation could be compared with each other. During the specified period, the articles from the sample did not lose their relevance and they managed to obtain a sufficient number of citations. We deliberately did not study the reviews for their belonging to one or another type of review publication, since often a review is understood as text that does not fall under the standards of a research article, including a description of programs, databases, methods, analytical equipment, etc. ${ }^{1}$

Table 1 shows the resulting sample of the 50 most highly cited reviews, sorted in order of decreasing citation.

Historically, different citation practices have developed in different branches of knowledge. Mathematicians are the least inclined to mention their colleagues among authors, representatives of the humanities and social sciences are somewhat more inclined, and physicists and chemists are much more likely to do so. Therefore, one citation in different sciences has a different weight, which means that the 50 most cited reviews under consideration are not necessarily the 50 most valuable to science. However, any such rating is subjective.

O.V. Mikhailov [58, p. 40] believes that publications on life sciences, biology, and medicine are most often the leaders in citation. According to another study, publications on biomedical, chemical, physical sciences, and artificial intelligence receive the largest number of citations, while publications of a general humanitarian orientation show modest citation results [59]. Our sample is consistent with these conclusions:

\footnotetext{
${ }^{1}$ We took the fact into account that a review article is recognized as such based on the choice of journal, the number of references to sources, the length of the article, associated keywords and the specified document type. These characteristics imply a choice both on the part of the author and on the part of the parties indexing the publication and having influence on the descriptors. That being said, we understand that if researchers claim that they are submitting a review article, then few journal editors are likely to disagree.
}

most of the reviews were from the fields of medicine (19 articles), chemistry (11), and biochemistry, genetics, and molecular biology (8).

All reviews in our sample were published in first quartile (Q1) journals. The top five most prolific journals include Chemical Reviews, Circulation, European Heart Journal (five articles each), Science (four) and Nature (three).

The distribution by the number of coauthors (Fig. 1) shows that a highly cited review with approximately the same probability can be prepared by a small group of 2 researchers, an average group of 6 to 10 people, and a team of more than 50 people. Highly cited reviews by one author are the least common, but one of them still ranked very high, in fourth place. Moreover, this article was published in the Neural Networks journal, whose other publications did not make our list. We note that in two publications on the standards of care for diabetes $(2013,2014)$, the authors are not identified, and the American Diabetes Association is listed as the collective author on the website of the Diabetes Care journal.

In terms of the number of authors of highly cited reviews, the United States is the strong leader among countries (Fig. 2). Authors from that country were involved in the preparation of more than half of these reviews. This leadership is most clearly seen in fractional authorship counts: American researchers contributed $40 \%$ (20 out of 50 fractional points) of the total author contributions and participated in reviews 4 times more often than authors from any other country. The second and third places are taken by Great Britain and France. Attention should be paid to the relatively modest representation of China and India, which in recent years have been among the top five countries in terms of the number of scientific publications. Russian researchers took part in four reviews as part of large teams of authors [9, 17, 22, 47], as evidenced by a fractional score of 0.12 .

\section{ANALYSIS OF THE CONTENT OF THE REVIEWS}

We conducted a content analysis of the listed reviews presented in Table 1 and summarized their content by research areas.

\section{Machine Learning}

The largest number of references in the sample, with a wide margin from the rest (18962 citations ${ }^{2}$ ) was obtained by an article "Deep learning" in Nature for 2015 [8]. Some people call the authors of this publication, Y. Lecun (h 74) ${ }^{3}$ together with G. Hinton and Y. Bengio, the Godfathers of Deep Learning ${ }^{4}$. In their

\footnotetext{
2 Citation data for articles were received in July 2020.

${ }^{3}$ In parentheses, hereinafter, is the author's Hirsch index.

${ }^{4}$ Author's translation.
} 
BAGIROVA et al.

\begin{tabular}{|c|c|c|c|c|c|c|c|c|c|c|c|c|}
\hline 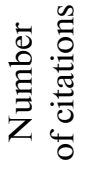 & $\mid \begin{array}{l}\tilde{\infty} \\
\infty \\
\cong\end{array}$ & $\vec{\infty}$ & $\frac{a}{i n}$ & $\stackrel{2}{\hat{n}}$ & 晑 & 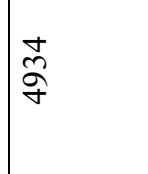 & 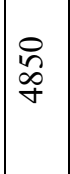 & 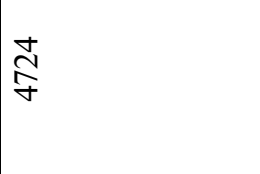 & $\begin{array}{l}\infty \\
\text { on } \\
\text { s. }\end{array}$ & $\frac{\infty}{\vec{f}}$ & $\frac{7}{b}$ & ֶે \\
\hline 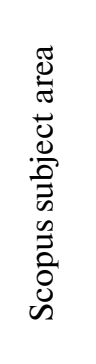 & 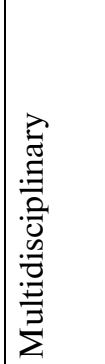 & 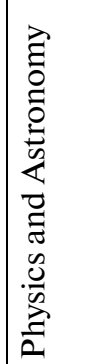 & 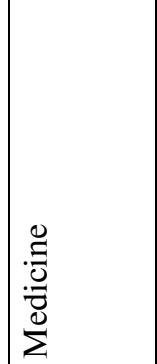 & 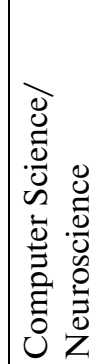 & 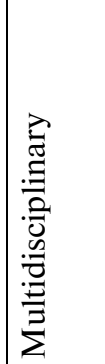 & 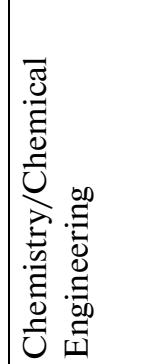 & 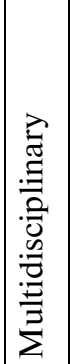 & 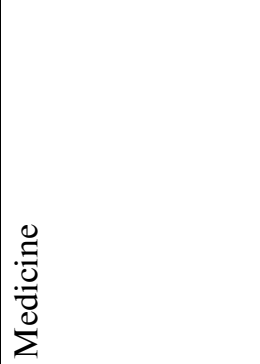 & 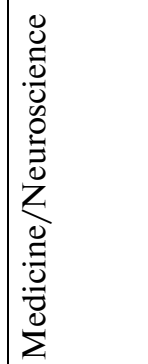 & 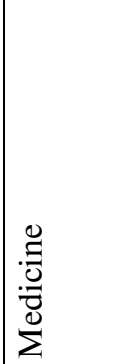 & 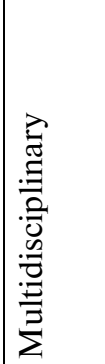 & 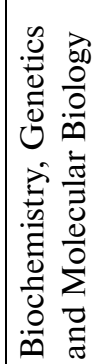 \\
\hline 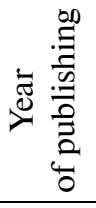 & $\stackrel{\text { ڤn }}{\grave{N}}$ & 离 & 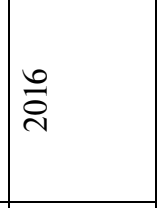 & iñ & $\stackrel{m}{\vec{i}}$ & $\stackrel{m}{\vec{\nu}}$ & $\stackrel{m}{\vec{\lambda}}$ & $\stackrel{\text { जे }}{a}$ & $\stackrel{0}{\stackrel{\sim}{\sim}}$ & 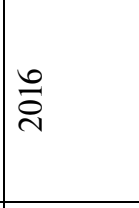 & 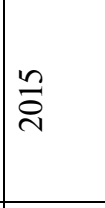 & $\stackrel{m}{\vec{i}}$ \\
\hline $\begin{array}{l}: 0 \\
\text { 音 } \\
\text { n }\end{array}$ & 意 & 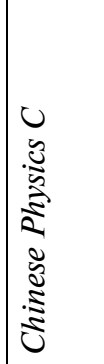 & 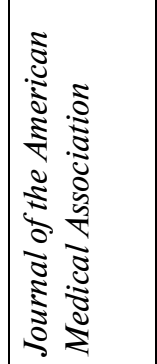 & 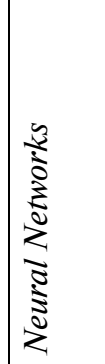 & 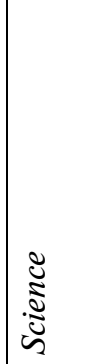 & 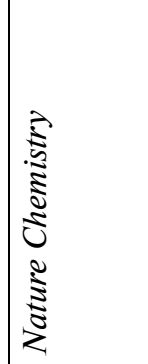 & 总 & 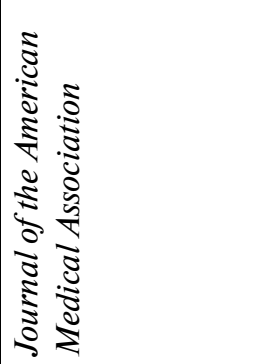 & 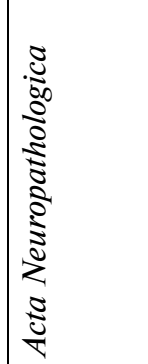 & 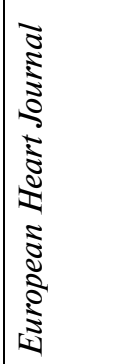 & 咅 & ঊ \\
\hline 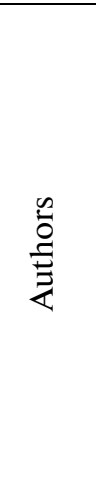 & 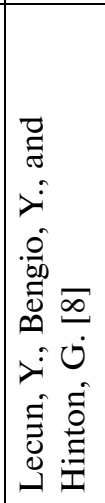 & 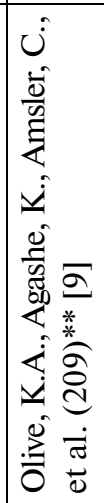 & 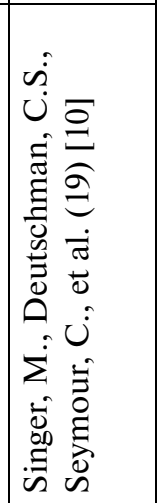 & 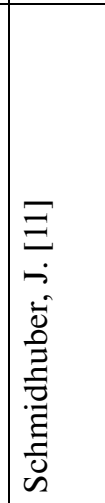 & 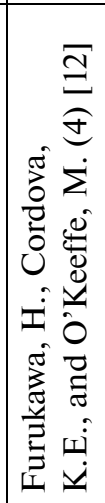 & 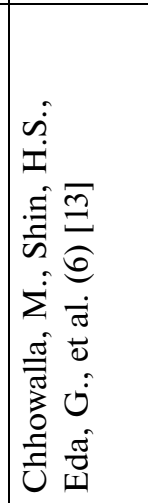 & 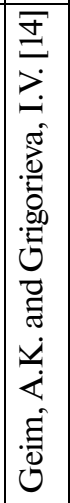 & 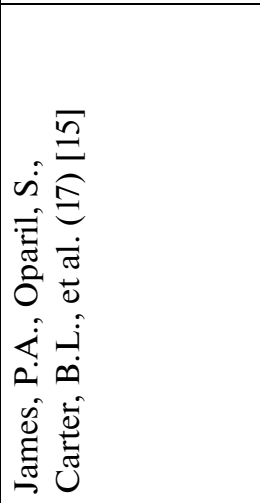 & 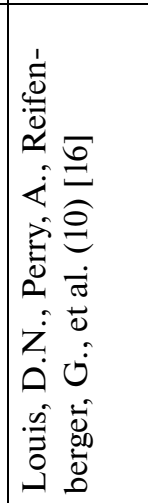 & 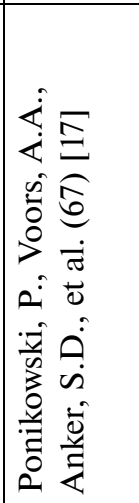 & 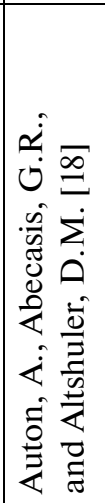 & 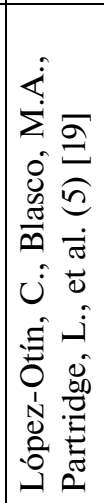 \\
\hline 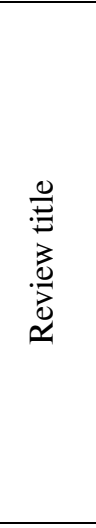 & 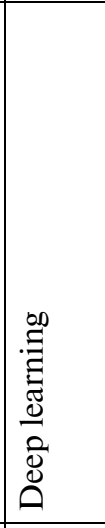 & 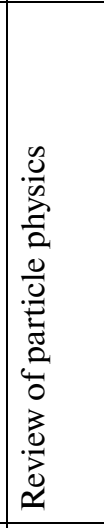 & 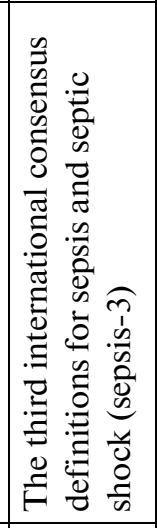 & 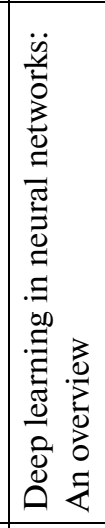 & 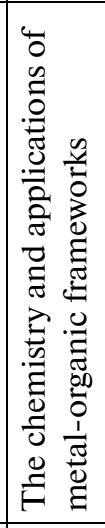 & 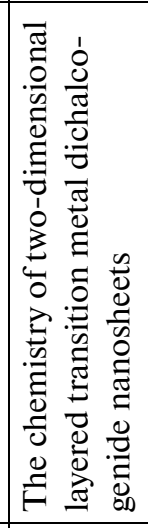 & 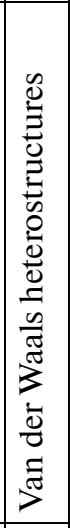 & 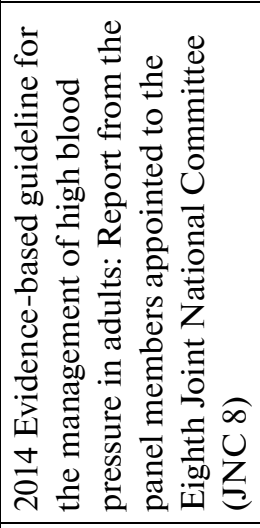 & 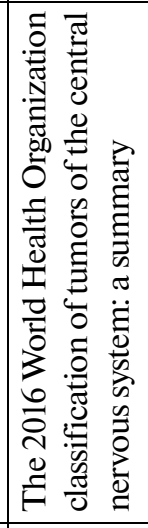 & 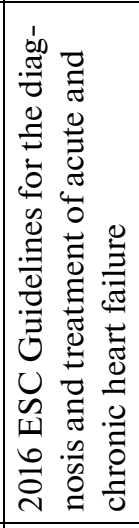 & 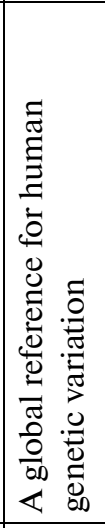 & 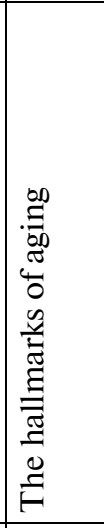 \\
\hline$\dot{z}$ & - & a & $m$ & $\sigma$ & in & 6 & $r$ & $\infty$ & $a$ & 인 & $=$ & $\simeq$ \\
\hline
\end{tabular}


THE 50 MOST HIGHLY CITED REVIEWS OF 2013-2017

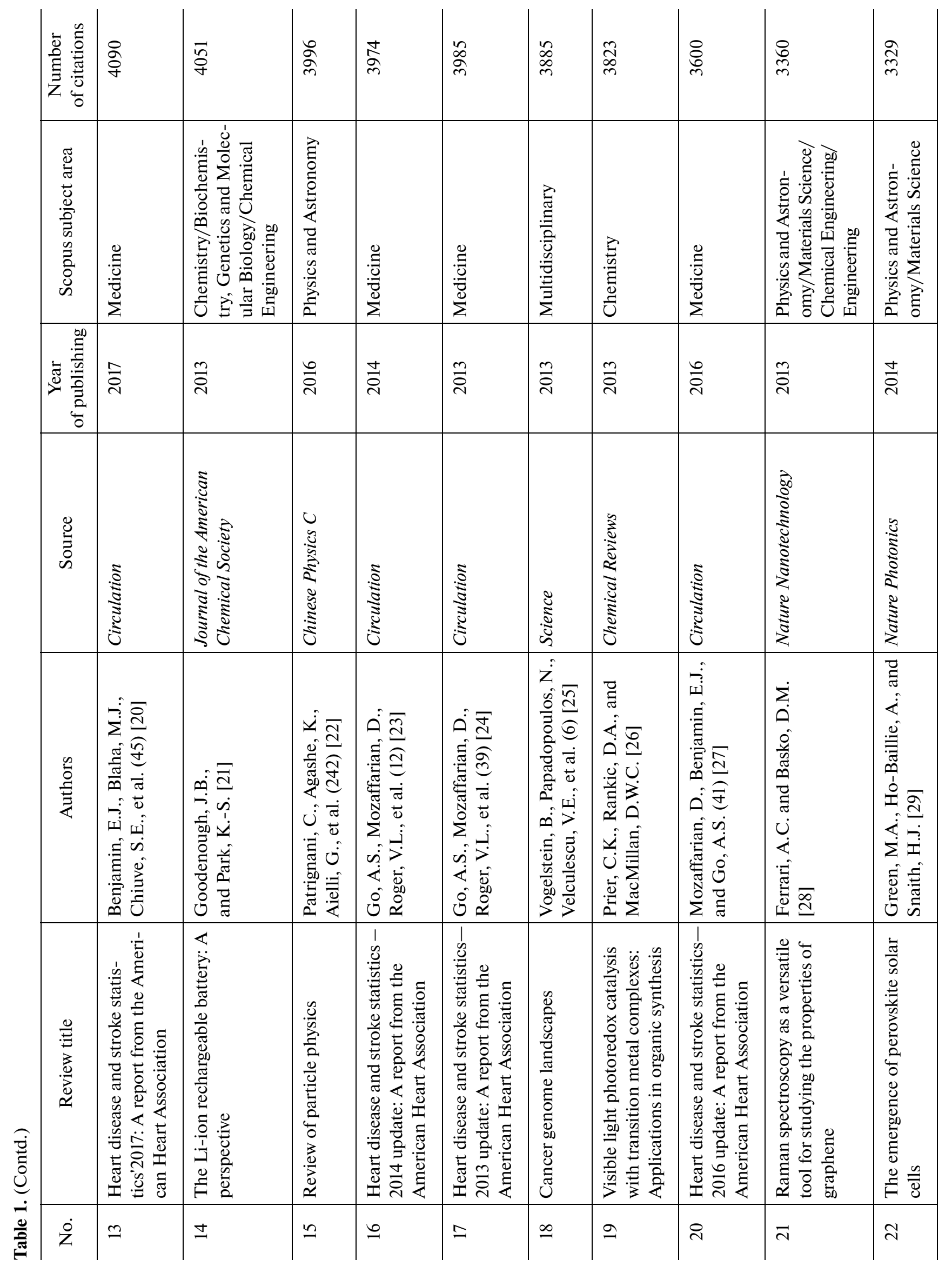

SCIENTIFIC AND TECHNICAL INFORMATION PROCESSING Vol. $48 \quad$ No. 32021 


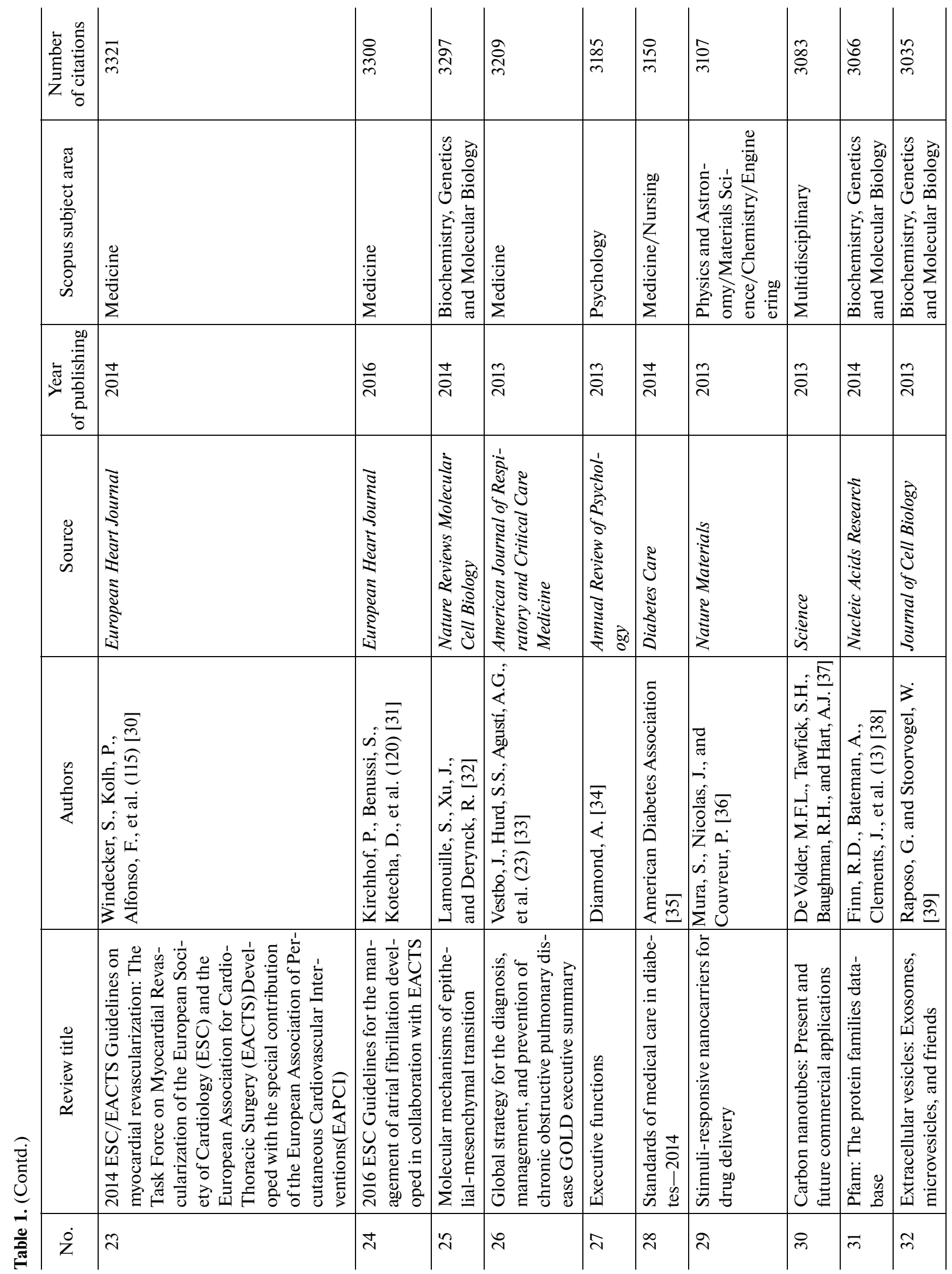

SCIENTIFIC AND TECHNICAL INFORMATION PROCESSING Vol. 48 No. 32021 
THE 50 MOST HIGHLY CITED REVIEWS OF 2013-2017

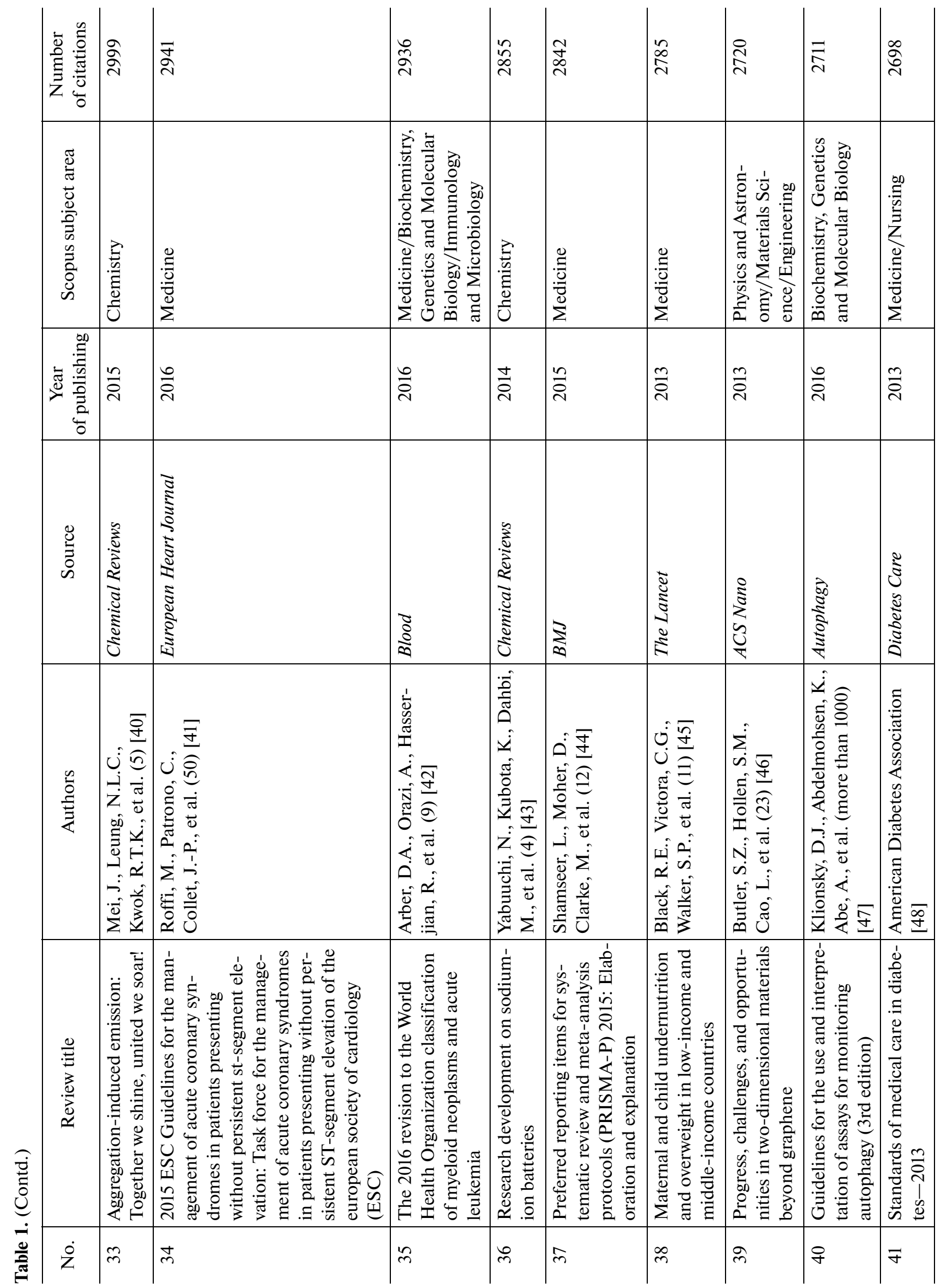

SCIENTIFIC AND TECHNICAL INFORMATION PROCESSING $\quad$ Vol. $48 \quad$ No. 32021 
BAGIROVA et al.

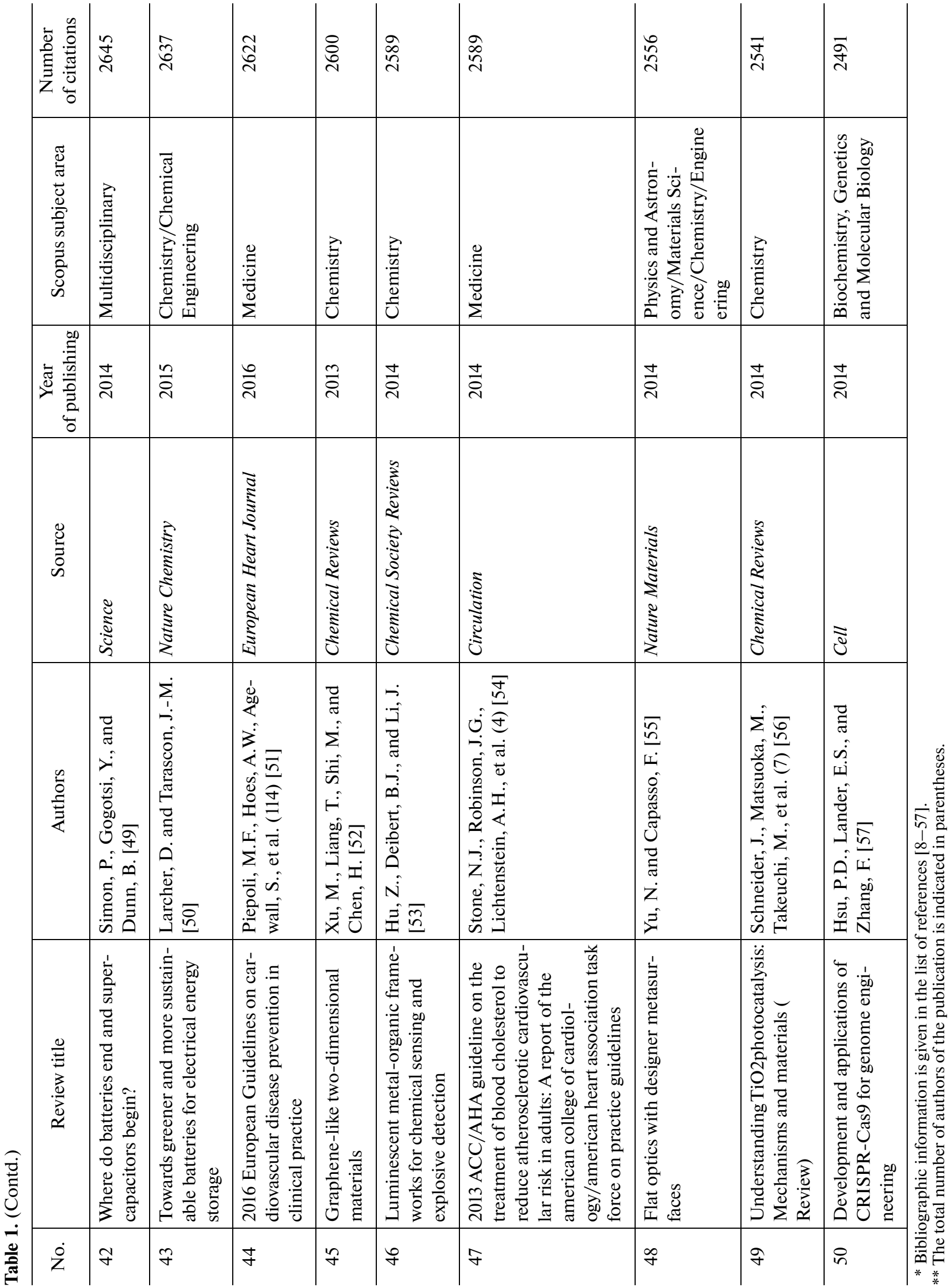




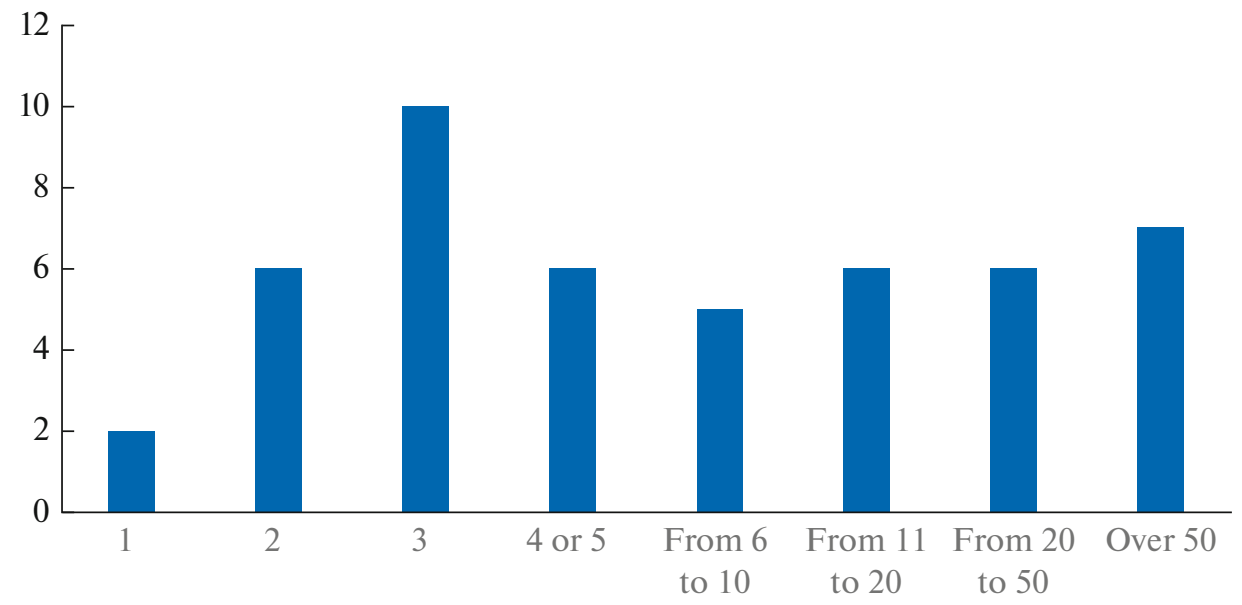

Fig. 1. The distribution of the number of reviews by the number of authors.

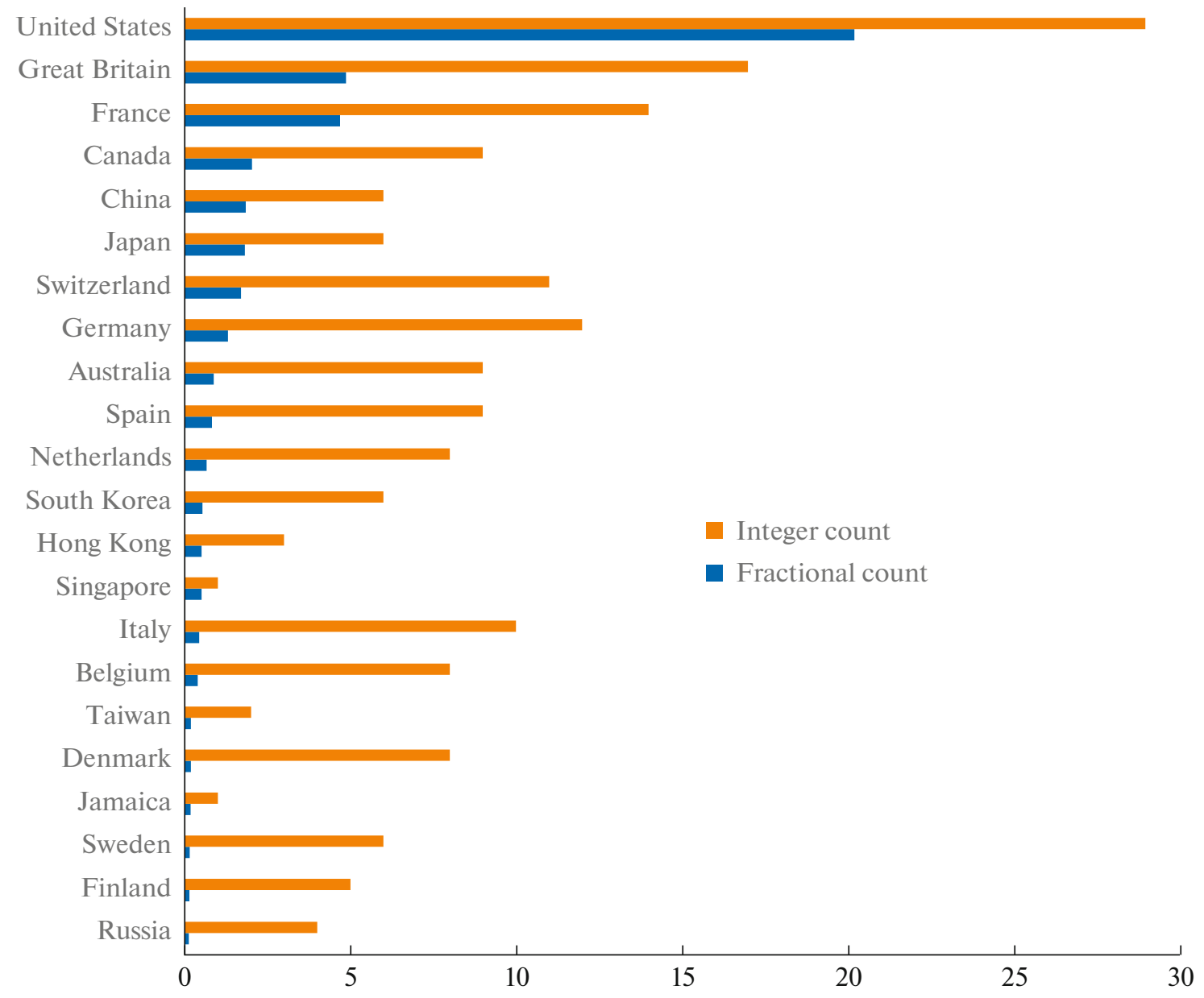

Fig. 2. The distribution of Top 50 reviews by countries by integer and fractional counts.

article, they reflected the basic concepts, methods, and technologies of supervised deep machine learning, which has become extremely popular and actively used in a variety of tasks. Thus, the terms of the phe- nomenal citation were authors, opinion leaders, who published an article in one of the most widely read scientific journals, who gave an exhaustive description of a wide class of machine learning technologies used in 
various fields. In Scopus, this survey has become the most highly cited in its field.

In addition, a survey is devoted to deep learning, which occupies the fourth position in our sample, "Deep learning in neural networks: An overview" (2015). Its author is Juergen Schmidhuber (Hirsch index 63), co-director of the Institute of Artificial Intelligence.

\section{Particle Physics}

The second place in our sample was a review on particle physics published in Chinese Physics $C$ (CiteScore $8.3^{5}$ ), a monthly peer-reviewed scientific journal of the Chinese Physical Society and the Institute of High Energy Physics of the Chinese Academy of Sciences in 2014 [9]. A review of 2016 from the same source is ranked 15th in the sample [22].

Reviews are made by the Particle Data Group (PDG); this is an international physics research community that studies elementary particles and collects and reanalyzes published results related to their properties and fundamental interactions. The reviews used a large amount of data on the topic, there are impressive lists of references (more than 400 sources). The highly cited Review of Particle Physics is published every 2 years. The high review rates had a significant effect on the Impact Factor of the Chinese Physics $C$ journal. This effect was described in detail in an article by W. Liu et al. [60]. Scientists have identified causal relationships where one highly cited article can significantly, but temporarily, increase the impact factor of a journal. Until 2013, Chinese Physics $C$ was classified as a Q4 journal and had a low impact factor (1.313). In addition, the total volume of publications in it, at that time, was no more than 200 a year. In 2014, the journal won a tender to publish a review in the field of particle physics, which may be partly due to the rapid growth of scientific research in China. After the publication of the review, the impact factor of Chinese Physics $C$ in 2015 increased to 3.761, and in 2016, to 5.514. Currently, according to Scopus, the journal belongs to Q1.

\section{Chemistry, Materials, and Energy}

In a large group of reviews, we included articles that in the Scopus distribution fell both to chemical categories and to multidisciplinary ones, but related to the field of chemistry. Innovations in the chemical industry often do not appear in isolation, but correlate with other areas of knowledge: physics, biology, ecology, waste disposal, alternative energy, and so on. The reviews presented in this group are united by topics,

\footnotetext{
${ }^{5}$ CiteScore (CS) of an academic journal is an indicator that reflects the average annual number of citations of the latest articles published in that journal. This journal score was launched in December 2016 by Elsevier as an alternative to commonly used JCR Impact Factors (IFs). (Hereinafter, metrics for July 2020).
}

that is, research areas in the field of high-tech materials, structures, and processes.

Over the past 15 years, the study of metal-organic frameworks and the development of these materials have become one of the most intensively and widely developed areas [61]. They are considered promising for storing hydrogen or methane for power generation and $\mathrm{CO}_{2}$ capture. Reviews that highlight the problems of metal-organic frameworks [12, 53] took the fifth and forty-sixth positions in Table 1.

Our sample included a number of reviews devoted to new hybrid nanomaterials. The author of the most cited article "Van der Waals heterostructures," A.K. Geim ${ }^{6}$ (h 91) is known primarily as one of the developers of the first method for producing graphene [14]. The identification of graphene among mechanically exfoliated graphite sheets and the subsequent discovery of its unusual electronic properties are attracting sustained interest in academia. This is evidenced by the fact that several reviews on the properties of graphene and two-dimensional materials [46, 52], including ultrathin two-dimensional nanosheets [13] and the analysis method, Raman spectroscopy [28], are included in the sample. If one rolls a sheet of graphene into a tube, there will be another nanomaterial, recognized by researchers as promising - carbon nanotubes. One highly cited publication presents research in the field of their synthesis, purification, and chemical modification [37]. In particular, carbon nanotubes are used in electrically responsive drug delivery systems. The review "Stimuli-responsive nanocarriers for drug delivery" describes the latest advances in the development of nanosystems that are able to control the biodistribution of drugs [36].

The review "Understanding $\mathrm{TiO}_{2}$ photocatalysis: Mechanisms and materials" [56] considered the results of studies of titanium oxide photocatalysts and their applications. Despite the emergence of various photocatalytic systems of binary oxides, $\mathrm{TiO}_{2}$ is considered the most promising material due to its excellent physicochemical properties, ease of synthesis, and relatively low cost [63]. $\mathrm{TiO}_{2}$ photocatalysts are widely used in environmental and energy applications, including self-cleaning surfaces, air and water purification systems, sterilization, hydrogen evolution, and photoelectrochemical conversion.

The review "Flat optics with designer metasurfaces" is devoted to recent developments in the field of flat ultrathin optical components called metasurfaces [55].

The review "Aggregation-induced emission: Together we shine, united we soar" describes aggregationinduced emission (AIE). This anomalous phenome-

\footnotetext{
${ }^{6}$ Nobel Prize Laureate in Physics (2010). Interestingly, a high correlation between bibliometrics and Nobel Prizes has been found and described in chemistry, medicine/physiology, and physics (Rodríguez-Navarro, 2011) [62].
} 
non has been observed with some organic phosphors (fluorescent dyes). It finds application, for example, in the field of biomaterials, in particular, to find and mark the location of proteins [40].

The publication "Visible light photoredox catalysis with transition metal complexes: Applications in organic synthesis" (2013) is devoted to photoredox catalysis [26]. One of the authors of the review, D. McMillan (h 97), is Professor Emeritus of Chemistry at Princeton University and a leading specialist in the field of asymmetric organic catalysis. In recent years, photoredox catalysis has been widely used in organic chemistry to activate small molecules.

Research related to the search for new sources of energy and methods of its conservation, which is one of the highest priority tasks in the field of energy [64], remains in high demand. The most cited areas are lithium-ion batteries [21], perovskite solar cells [29], sodium-ion batteries [43], supercapacitors [49], and energy conservation technologies [50].

Reviews of this group have been published in the following journals: Science (CiteScore 45.3), Nature Chemistry (38.2), Nature (51.0), Journal of the American Chemical Society (24.8), Chemical Reviews (100.5), Nature Nanotechnology (59.4), Nature Photonics (58.3), Nature Materials (63.3), ACS Nano (23.5), and Chemical Society Reviews (67.1).

\section{Medicine}

The amount of medical information is rapidly growing in the world, which requires constant monitoring and updating of data from specialists in this field [65]. It is not surprising that large medical organizations are trying to quickly communicate clinical changes, the diagnosis and treatment of individual diseases, while studying, generalizing, classifying, and processing data in a new way.

Experts from all over the world are involved in writing review publications on widespread and socially significant diseases. Such diseases include, for example, a number of pathologies of the cardiovascular system, oncological diseases, diabetes mellitus, chronic obstructive pulmonary disease (COPD) [66], which for the last 15 years have been included in the WHO list as the main causes of death in the world [64]. They have high risk factors such as obesity, smoking, an unhealthy diet, and environmental factors. In addition to frequent mortality, these pathologies have a high threshold of disability of the population, thereby increasing the socio-economic burden on society. All this raises concern, which leads to an increase in funding for medical research, the number of projects and the number of researchers involved in them.

Given the above, we assumed that highly cited medical reviews will more often refer to pathologies that are more likely to become causes of death. For verification, we compared the topics of the reviews with the ten most common causes of death according to the World Health Organization (Fig. 3).

In fact, out of 18 medical reviews in our sample, 12 are associated with circulatory diseases, including coronary heart disease, high blood pressure, and stroke, which are in the first two places of the WHO ranking. One review refers to COPD (third place) and two reviews refer to diabetes (ninth place). Another survey, "Maternal and child undernutrition and overweight in low-income and middle-income countries," which describes not only the medical, but also the socially significant problem of malnutrition and overweight among mothers and children in low and middle income countries [45], is closely related to the themes of neonatological pathologies (fifth place) and diarrhea (eighth place), which is often a consequence of malnutrition and mortality in children under 5 years of age. Finally, our sample contains a review of cancer genome studies, "Cancer genome landscapes" (sixth place) [25].

Thus, out of the ten most common causes of death in our sample of reviews, seven are present. We note that another review on the spread of dementia, "The global prevalence of dementia: A systematic review and metaanalysis" (seventh place), almost entered our sample; it is in 63rd place. It can be added that a review describing the state and prospects of chronic kidney disease ranks 124th.

We were unable to find highly cited reviews on infectious diseases. Perhaps, this is due to the changing nature of infectious diseases that require more frequent data updates; accordingly, current reviews do not have time to obtain a large number of citations. Unfortunately, the emergence of COVID-19 is likely to fill this gap.

Let us consider the topics of medical reviews and the context of their preparation in more detail.

The most cited medical review was the article "The third international consensus definitions for sepsis and septic shock (sepsis-3)" on the problems of definition of sepsis and septic shock. These definitions were last revised in 2001. The expert task force was organized by the Society of Resuscitation and the European Society of Intensive Care Medicine, whose members have extensive experience in defining the pathobiology and epidemiology of sepsis; they have conducted relevant clinical trials and provided their recommendations to specialists [10].

The review "Evidence-based guideline for the management of high blood pressure in adults: Report from the panel members appointed to the Eighth Joint National Committee (JNC 8)" was carried out by a group of experts from the United States, whose members were selected based on their experience in the field of hypertension, primary health care, including geriatrics, cardiology, nephrology, nursing, pharmacology, clinical trials, evidence-based medicine, epidemiology, informatics, and the development and 


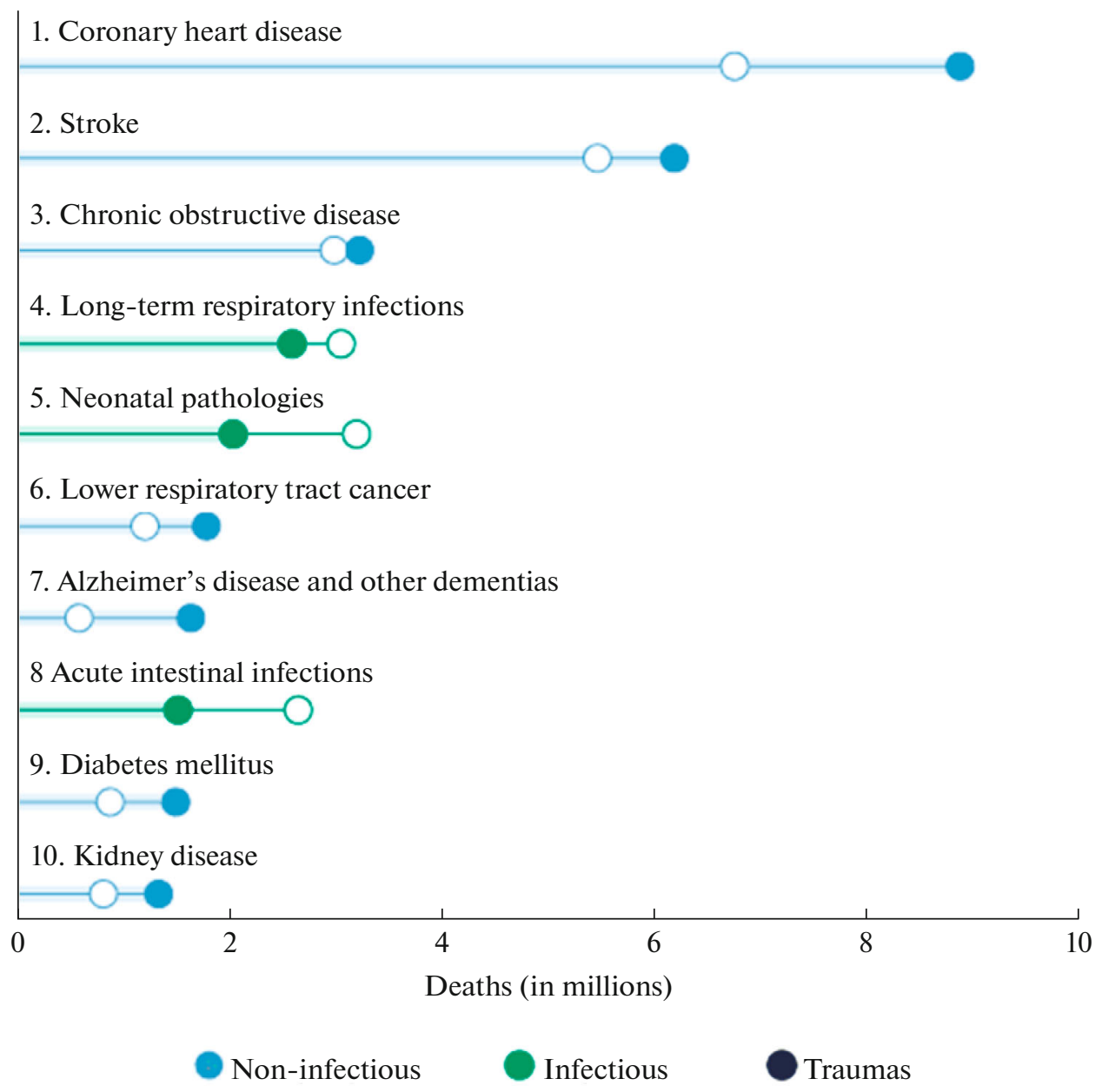

Source: WHO Global Health Estimates

Fig. 3. The most common causes of death (according to the World Health Organization [64]).

implementation of clinical guidelines in health systems [15]. The two most cited reviews [10, 15] were published in the American Medical Association's weekly international medical journal (JAMA, CiteScore 26.3).

The Task Force on myocardial revascularization of the European Society of Cardiology (ESC) and the European Association of Cardio-Thoracic Surgery (EACTS) issue annual guidelines for clinicians in the form of reviews based on rigorous analysis of the scientific evidence that is available during preparation. Reviews are published in the European Heart Journal (CiteScore 23.7). Our sample included five reviews published in this journal [17, 30, 31, 41, 51].

The American Heart Association (AHA) collaborates with the centers for disease control and prevention, the national institutes of health, and other government agencies to collect the latest statistics on heart disease, stroke, and other cardiovascular and metabolic diseases and present them in its statistical update on cardiovascular diseases and strokes. Reviews of this group are published in the journal published by Lippincott Williams \& Wilkins for the American Heart Association, Circulation (CiteScore 25.2). The journal publishes articles related to the research and practice of cardiovascular disease, including observational research, clinical trials, epidemiology, health services, and advances in basic and translational research. Our sample included five reviews published in Circulation [20, 23, 24, 27, 54]. Thus, 50 highly cited reviews included 10 publications from the fields of cardiology and cardiovascular medicine at once. Two of them, which refine the existing classifications of diseases, were carried out with the direct involvement of the World Health Organization. The first article, "The 2016 World Health Organization classification of tumors of the central nervous system: A summary," 
revises the classification of tumors of the central nervous system by the World Health Organization (WHO) and, according to the authors, reflects conceptual and practical progress compared to the previous version of 2007 [16]; the second, "The 2016 revision to the World Health Organization classification of myeloid neoplasms and acute leukemia," was prepared by the American Society of Hematology [42] and is a revision of the WHO classification of hematopoietic and lymphoid tissue tumors (previously, the data were updated in 2008).

Another major medical problem is the incidence of diabetes mellitus. In 1980 the number of patients was 108 million; in 2014 it was 422 million [64]. The reviews "Standards of medical care in diabetes" of 2013 and 2014, published in the respected medical journal Diabetes Care include screening, diagnosis, and therapeutic interventions [35, 48]. The American Diabetes Association (ADA) is the author of the reviews; one of the tasks of the association is to regularly update the Standards of Care for Patients with Diabetes Mellitus.

Chronic obstructive pulmonary disease (COPD), a pathology that includes the terms emphysema and chronic bronchitis, is also a widespread disease. The review of the American Thoracic Society's "Global strategy for the diagnosis, management, and prevention of chronic obstructive pulmonary disease GOLD executive summary" obtained 3202 citations [33].

In terms of growth rates, the volume of systematic reviews and meta-analyses in medicine is ahead of other fields. Therefore, it was not surprising that the review "Preferred reporting items for systematic review and meta-analysis protocols (PRISMA-P) 2015: Elaboration and explanation," which provides guidance on increasing the transparency, accuracy, completeness, and frequency of documented systematic reviews and meta-analyses, developed by an international group of experts, appeared in our sample. The PRISMA-P checklist contains 17 items that are considered essential and minimum necessary components of a systematic review or meta-analysis protocol [44].

\section{Biochemistry, Genetics, and Molecular Biology}

Highly cited publications on molecular biology have influenced future advances in this area, as the authors of the article "The 100 most-cited articles from JMB" concluded [68]. It is possible that the reviews presented in our study will also have a significant impact on the emergence of new original studies. As examples, the publications "A global reference for human genetic variation" [18], "Cancer genome landscapes" [25], and "Pfam: The protein families database" systematize genetic studies and contribute to the formation of collections of gene variations and protein databases.
Several highly cited reviews have been devoted to various molecular mechanisms, in particular, studies in the field of aging [19], epithelial-mesenchymal transition [32], and the formation of extracellular vesicles [39]. Separately, we can highlight the updated ${ }^{7}$ set of guidelines for standardizing autophagy research ${ }^{8}$ [47], as well as an article on genome editing technology based on programmable nucleases ${ }^{9}$ Cas9 [57].

The review "Executive functions," which describes executive functions, is presented separately, since its subject, developmental psychology, does not fit into any of the groups presented here [34]. The author, A. Diamond (h 45), identified a biological mechanism that causes a deficit in executive function in children treated for phenylketonuria (PKU); he is included in 18 external advisory boards and 8 editorial boards of all three major developmental psychology journals [69].

\section{RUSSIAN REVIEW PRACTICE}

The authors' teams of our sample included 17 representatives of Russia. They participated in reviews of particle physics most actively. Out of 11 people, 9 represent the Institute of High Energy Physics (Moscow). In addition to them, the coauthors included S.I. Eidelman (Budker Institute of Nuclear Physics SB RAS, Novosibirsk, h 60) and A.S. Romanyuk (National Research Nuclear University MEPhI, Moscow, h 106).

Five authors from Russia took part in a review on autophages: they are employees of the Kazan Institute of Biochemistry and Biophysics of the Kazan Scientific Center, Russian Academy of Sciences (Kazan), the Komarov Botanical Institute, Russian Academy of Sciences (St. Petersburg), St. Petersburg University, the Nasonova Research Institute of Rheumatology (Moscow), and the Lomonosov Moscow State University [47].

Among the authors' groups of medical reviews included in the sample, there was only one coauthor from Russia: a representative of the Russian Society of Cardiology, E.V. Shlyakhto, a Russian scientist, cardiologist, and Academician of the Russian Academy of Sciences (h 33). On behalf of the Russian Society of Cardiology, he took part in the review "2016 ESC Guidelines for the diagnosis and treatment of acute and chronic heart failure," which received more than 4500 citations. For comparison, the most highly cited Russian review in the field of heart failure, "Russian heart failure society, Russian society of cardiology. Russian scientific medical society of internal medicine guidelines for heart failure: Chronic (CHF) and acute

\footnotetext{
7 The first review was published in 2008.

${ }^{8}$ The autophagy process is encoded in the genome and can serve as a basis for increasing the effectiveness of methods of treating malignant neoplasms.

${ }^{9}$ RNA-guided endonucleases, known as Cas9, from the microbial adaptive immune system CRISPR can easily target virtually any place in the genome.
} 
decompensated (ADHF). Diagnosis, prevention, and treatment" published in the authoritative Russian journal Cardiology in 2018 has only 78 citations in Scopus [70].

One of the reasons for the low citation rate of Russian scientists is that in our country medical teaching materials often do not fall into the main scientific document flow at all. This is indicated by A.A. Mzhelsky and O.V. Moskaleva:

"... the guidelines of associations are usually published in brochures and come out in separate runs or published on the portals of ministries, where sometimes the authors are not indicated at all, or the group of authors is indicated at the end of the document, but due to the lack of republishing in scientific journals, authors do not receive any citation .... An example of one of the few Russian journals that publishes national guidelines could be the journal Sakharnyi Diabet (Diabetes Mellitus), in which the Diabetes Mellitus Guidelines published in 2007 as of June 28, 2020 had 111 citations. If we take into account the journal's citation rate $($ CiteScoreTracker $2020=1.5)$, then this article was cited 74 times more often than the average. Since this is a rare practice for Russian journals and authors (especially in the field of medicine), this puts them in an unequal position with foreign competitors in the same subject area, underestimating their bibliometric indicators, and, in particular, leaving journals in the lower quartiles" [71].

There are also other reasons for the modest results in citing Russian medical specialists; these were stated by Verbitskaya ${ }^{10}$ on the web pages of the Russian Chapter of the Cochrane Collaboration. These include the unsatisfactory presentation of abstracts from Russian journals in international databases such as PubMed, the lack of a function for uploading the corresponding links to bibliographic managers, the publication of articles on the Internet only in PDF format, which makes it difficult or impossible to link to articles of our authors when working with search engines in English. In addition, the low quality of clinical trials, unsatisfactory performance of statistical analysis and presentation of the results also prevent Russian medical science from reaching a decent level (cited from [72]).

The situation with Russian surveys is well characterized by the use of PRISMA protocols ${ }^{11}$, as included in our list of highly cited reviews [44]. To reduce the influence of human and other factors leading to the distortion of research, the scientific community forms

\footnotetext{
${ }^{10}$ Elena Vladimirovna Verbitskaya is the Researcher at Cochrane Russia, Associate Professor of the Department of Clinical Pharmacology and Evidence-Based Medicine, Head of the Department of Pharmacoepidemiology and Biomedical Statistics of the Waldman Institute of Pharmacology of the Pavlov St. Petersburg State Medical University.

${ }^{11}$ Preferred Reporting Items for Systematic Reviews and MetaAnalyses (formerly QUOROM).
}

special rules. The application of these rules is widespread in the medical community. Thus, the use of the PRISMA protocols is encouraged by reputable journals that publish medical research, some of which refer to these protocols in their guidelines for authors; some journals require authors to adhere strictly to them. Some of the foreign reviews carried out using the PRISMA protocols are pre-registered on the PROSPERO platform ${ }^{12}$, which plays the role of an international register of systematic reviews. Registration helps to avoid duplication and reduce the possibility of bias in the assessment of the data provided by allowing the completed review to be compared with what was planned in the protocol. Reputable journals such as PLoS, BMJ and BMJ Open, BioMed, Central, and BJOG recommend pre-registering systematic reviews in guidelines for authors, including registration data in manuscripts, making these records and research protocols available to reviewers and editors, as well as readers of published reviews.

Recently, Russian researchers have started using PRISMA, although not very actively. On the eLIBRARY.ru platform, only 34 reviews were found in whose annotations the use of the PRISMA protocols was declared. Of these publications, 13 were prepared in 2020, 11 in 2019, 3 in 2018, 4 in 2017, 1 in 2016, and 2 in 2015.

At the same time, the so-called narrative review type prevails in the total mass of medical reviews by Russian authors (the author's vision of the problem, supported by literature sources). As a result, such often "subjective" reviews in the field of medicine are practically not cited in the West and are not accepted in foreign journals, and Russian journals with such reviews (without systematic reviews) are usually denied indexing in specialized international scientific databases such as Medline [71].

\section{CONCLUSIONS}

Review articles are an important part of the scientific document flow. They systematize various studies, form a general picture of the current state of affairs, the most important results, the methods used, and research fronts for the reader. Good reviews in the scientific community are highly valued, as evidenced, in particular, by their high level of citation in scientific publications. The study of the most cited reviews allows one to form an idea of the most important research fronts for the scientific community.

Our sample of highly cited reviews came from industry-leading Q1 journals (by bibliometrics and expert opinion). That being said, there are cases where a series of highly cited reviews can significantly raise a journal's rating.

\footnotetext{
${ }^{12}$ PROSPERO is developed and supported by the University of York Access and Outreach Center and funded by the National Institute for Health Research (NIHR).
} 
Medicine (18), chemistry (13), biochemistry, genetics, and molecular biology (8) were the leading topics among the 50 most cited reviews we selected for the study. Many of them were written in the format of regularly updated reviews of the results of relevant research with the participation of authoritative groups of experts from the world's leading scientific institutions. Some of the reviews were written in the framework of international collaborations (internationally collaborative reviews; this concept was first introduced by Yu.S. Ho and M. Kahn, such work implies the participation of scientists from different universities in the world in their preparation [73]). In many fields of science, the regular release of systematic reviews is carried out on behalf of national and international associations, which thus keep up to date, disseminate extensive and constantly evolving knowledge among researchers, systematizing and comparing them along the way. Such activities require significant efforts of leading representatives of the scientific community, but their contribution saves more time for other researchers and helps them avoid erroneous decisions and make new discoveries faster.

The G7 countries were in the lead both by integer and fractional counts, it is in these countries that the most authoritative scientific organizations on a global scale are located; the active participation of authors from these significantly increases the chances of a successful review. An article can be written both by large groups of authors and by small groups of two to three researchers. There are cases when the author of a highly cited review is one person, but this must be a recognized specialist in their field. In each case, at least one author from the group of authors must have a Hirsch index higher than 45. Interestingly, Eugene Garfield $^{13}$ came to the conclusion that among the $0.1 \%$ level of the best authors, a significant proportion of them had received the Nobel Prize or would receive it in subsequent years [74]. In our case, an example of such an effect was the authorship of the review devoted to the properties of graphene by the Nobel laureate of 2010 A.K. Geim [14].

Unfortunately, today in Russia there is no practice of annual generalization of scientific data in the form of reporting, recommendation, and other review publications that would be highly cited and recognized by the international scientific community. The texts called scientific reviews are published in special review periodicals and continuing editions Annual Reviews, Yearbooks, Scientific Review, Annals, in issues of Abstract Journals of the VINITI and INION, Russian Academy of Sciences, in journals published by scientific societies, in collections of departmental informa-

\footnotetext{
${ }^{13}$ Eugene Garfield, founder of the Institute for Scientific Information (ISI, Philadelphia, PA, now Thomson Reuters, New York, NY), was one of the first to systematically use citation analysis to identify potential Nobel Prize winners based on their publication citation ratings.
}

tion services: Central Scientific Research Institute of Information and Feasibility Studies of Oil Refining and Petrochemical Industry, All-Russian Research Institute for Problems in Scientific and Technical Progress and Information in Civil Engineering, Research Institute of Higher Education, Informavtodor, and others). Scientific reviews are also published in primary periodicals and continuing editions (mainly, these are journals, the names of which begin with the words Uspekhi ..., Dostizheniya ..., Sovremennye Problemy ..., Advances in ..., Progress in ...). These journals can be profiled by branches of science (Uspekhi Khimii, Uspekhi Fiziologicheskikh Nauk), and multidisciplinary (Uspekhi Sovremennogo Estestvoznaniya). Such publications are mainly located in the closed system of Russian scientific communications, focused on the domestic researcher.

Our analysis covered only a small fraction of the highly cited review publications. The authority of the scientist and the team, the high relevance of the subject of the review, as well as the rating of the source, significantly increase the demand for the document. We believe that the most important conclusion is the need to pay more attention to writing reviews when planning research projects, training graduate students, and improving the qualifications of young scientists.

\section{REFERENCES}

1. Guskov, A.E., Kosyakov, D.V., Bagirova, A.V., and Blinov, P.Yu., Citation factors of reviews, Bull. Russ. Acad. Sci., 2020, vol. 90, no. 12, p. 1128-1140. https://doi.org/10.31857/S086958732012021X

2. Haunschild, R. and Bornmann, L., Normalization of Mendeley reader counts for impact assessment, J. Informetrics, 2016, vol. 10, no. 1, pp. 62-73. https://doi.org/10.1016/j.joi.2015.11.003

3. Grant, M.J. and Booth, A., A typology of reviews: An analysis of 14 review types and associated methodologies, Health Inf. Libr. J., 2009, vol. 26, no. 2, pp. 91108.

4. Sutton, A., Clowes, M., Preston, L., and Booth, A., Meeting the review family: Exploring review types and associated information retrieval requirements, Health Inf. Libr. J., 2019, vol. 36, no. 3, pp. 202-222.

5. Horsley, T., Tips for improving the writing and reporting quality of systematic, scoping, and narrative reviews, J. Continuing Educ. Health Prof., 2009, vol. 39, no. 1 , pp. 54-57.

6. Arksey, H. and O'Malley, L., Scoping studies: Towards a methodological framework, Int. J. Soc. Res. Methodol., 2005, vol. 8, no. 1, pp. 19-32. https://doi.org/10.1080/1364557032000119616

7. Paré, G., Trudel, M.-C., Jaana, M., and Kitsiou, S., Synthesizing information systems knowledge: A typology of literature reviews, Inf. Manage., 2015, vol. 52, no. 2, pp. 183-199.

8. Lecun, Y., Bengio, Y., and Hinton, G., Deep learning, Nature, 2015, vol. 521, no. 7553, pp. 436-444.

https://doi.org/10.1038/nature 14539 
9. Olive, K.A., Agashe, K., Amsler, C., et al., Review of particle physics, Chin. Phys. C, 2014, vol. 38, no. 9, p. 090001.

https://doi.org/10.1088/1674-1137/38/9/090001

10. Singer, M., Deutschman, C.S., Seymour, C., et al., The third international consensus definitions for sepsis and septic shock (sepsis-3), JAMA, J. Am. Med. Assoc., 2016, vol. 315, 801-810.

https://doi.org/10.1001/jama.2016.0287

11. Schmidhuber, J., Deep learning in neural networks: An overview, Neural Networks, 2015, vol. 61, pp. 85-117. https://doi.org/10.1016/j.neunet.2014.09.003

12. Furukawa, H., Cordova, K.E., O'Keeffe, M., and Yaghi, O.M., The chemistry and applications of metalorganic frameworks, Science, 2013, vol. 341, no. 6149, p. 1230444. https://doi.org/10.1126/science.1230444

13. Chhowalla, M., Shin, H.S., Eda, G., Li, L.-J., Loh, K.P., and Zhang, H., The chemistry of two-dimensional layered transition metal dichalcogenide nanosheets, Nat. Chem., 2013, vol. 5, no. 4, pp. 263-275. https://doi.org/10.1038/nchem.1589

14. Geim, A.K. and Grigorieva, I.V., Van der Waals heterostructures, Nature, 2013, vol. 499, no. 7459, pp. 419425. https://doi.org/10.1038/nature 12385

15. James, P.A., Oparil, S., Carter, B.L., et al., 2014 evidence-based guideline for the management of high blood pressure in adults: Report from the panel members appointed to the Eighth Joint National Committee (JNC 8), JAMA, J. Am. Med. Assoc., 2014, vol. 311, no. 5 , pp. $507-520$. https://doi.org/10.1001/jama.2013.284427

16. Louis, D.N., Perry, A., Reifenberger, G., et al., The 2016 World Health Organization Classification of Tumors of the Central Nervous System: A summary, Acta Neuropathol., 2016, vol. 131, no. 6, pp. 803-820. https://doi.org/10.1007/s00401-016-1545-1

17. Ponikowski, P., Voors, A.A., Anker, S.D., et al., 2016 ESC Guidelines for the diagnosis and treatment of acute and chronic heart failure, Eur. Heart J., 2016, vol. 37, no. 27, pp. 2129-2200.

https://doi.org/10.1093/eurheartj/ehw128

18. Auton, A., Abecasis, G.R., Altshuler, D.M., Durbin, R.M., Bentley, D.R., Chakravarti, A., and Clark, A.G., A global reference for human genetic variation, Nature, 2015, vol. 526, no. 7571, pp. 68-74.

https://doi.org/10.1038/nature 15393

19. López-Otín, C., Blasco, M.A., Partridge, L., Serrano, M., and Kroemer, G., The hallmarks of aging, Cell, 2013, vol. 153 , no. 6 , pp. 1194 .

https://doi.org/10.1016/j.cell.2013.05.039

20. Benjamin, E.J., Blaha, M.J., Chiuve, S.E., et al., Heart Disease and Stroke Statistics'2017 Update: A report from the American Heart Association, Circulation, 2017, vol. 135, no. 10, pp. e146-e603. https://doi.org/10.1161/CIR.0000000000000485

21. Goodenough, J.B. and Park, K.-S., The Li-ion rechargeable battery: A perspective, J. Am. Chem. Soc., 2013, vol. 135, no. 4, pp. 1167-1176.

https://doi.org/10.1021/ja3091438
22. Patrignani, C., Agashe, K., Aielli, G., et al., Review of particle physics, Chin. Phys. C, 2016, vol. 40, no. 10, p. 100001.

https://doi.org/10.1088/1674-1137/40/10/100001

23. Go, A.S., Mozaffarian, D., Roger, V.L., et al., Heart Disease and Stroke Statistics - 2014 Update: A report from the American Heart Association, Circulation, 2014, vol. 129, no. 3, pp. e28-e292. https://doi.org/10.1161/01.cir.0000441139.02102.80

24. Go, A.S., Mozaffarian, D., Roger, V.L., et al., Heart Disease and Stroke Statistics-2013 Update: A report from the American Heart Association, Circulation, 2013, vol. 127, no. 1, pp. e6-e245.

https://doi.org/10.1161/CIR.0b013e31828124ad

25. Vogelstein, B., Papadopoulos, N., Velculescu, V.E., et al., Cancer genome landscapes, Science, 2013, vol. 340 , no. 6127 , pp. $1546-1558$.

https://doi.org/10.1126/science. 1235122

26. Prier, C.K., Rankic, D.A., and MacMillan, D.W.C., Visible light photoredox catalysis with transition metal complexes: Applications in organic synthesis, Chem. Rev., 2013, vol. 113, no. 7, pp. 5322-5363. https://doi.org/10.1021/cr300503r

27. Mozaffarian, D., Benjamin, E.J., Go, A.S., et al., Heart Disease and Stroke Statistics-2016 Update: A report from the American Heart Association, Circulation, 2016, vol. 133, no. 4, pp. e38-e48. https://doi.org/10.1161/CIR.0000000000000350

28. Ferrari, A.C. and Basko, D.M., Raman spectroscopy as a versatile tool for studying the properties of graphene, Nat. Nanotechnol., 2013, vol. 8, no. 4, pp. 235-246. https://doi.org/10.1038/nnano.2013.46

29. Green, M.A., Ho-Baillie, A., and Snaith, H.J., The emergence of perovskite solar cells, Nat. Photonics, 2014, vol. 8, no. 7, pp. 506-514.

https://doi.org/10.1038/nphoton.2014.134

30. Windecker, S., Kolh, P., Alfonso, F., et al., 2014 ESC/EACTS Guidelines on myocardial revascularization: The Task Force on Myocardial Revascularization of the European Society of Cardiology (ESC) and the European Association for Cardio-Thoracic Surgery (EACTS) developed with the special contribution of the European Association of Percutaneous Cardiovascular Interventions (EAPCI), Eur. Heart J., 2014, vol. 35 , no. 37 , pp. $2541-2619$. https://doi.org/10.1093/eurheartj/ehu278

31. Kirchhof, P., Benussi, S., Kotecha, D., et al., 2016 ESC Guidelines for the management of atrial fibrillation developed in collaboration with EACTS, Eur. Heart J., 2016, vol. 37, no. 38 .

https://doi.org/10.1093/eurheartj/ehw210

32. Lamouille, S., Xu, J., and Derynck, R., Molecular mechanisms of epithelial-mesenchymal transition, Nat. Rev. Mol. Cell Biol., 2014, vol. 15, no. 3, pp. 178196. https://doi.org/10.1038/nrm3758

33. Vestbo, J., Hurd, S., S., Agustí, A.G., et al., Global strategy for the diagnosis, management, and prevention of chronic obstructive pulmonary disease GOLD executive summary, Am. J. Respir. Crit. Care Med., 2013, vol. 187 , no. 4 , pp. $347-365$.

https://doi.org/10.1164/rccm.201204-0596PP 
34. Diamond, A., Executive functions, Annu. Rev. Psychol., 2013, no. 64, pp. 135-168.

https://doi.org/10.1146/annurev-psych-113011-143750

35. Standards of Medical Care in Diabetes-2014, Diabetes Care, 2014, vol. 37, suppl. 1, pp. S14-S80. https://doi.org/10.2337/dc14-S014

36. Mura, S., Nicolas, J., and Couvreur, P., Stimuli-responsive nanocarriers for drug delivery, Nat. Mater., 2013, vol. 12, no. 11, pp. 991-1003. https://doi.org/10.1038/nmat3776

37. De Volder, M.F.L., Tawfick, S.H., Baughman, R.H., and Hart, A.J., Carbon nanotubes: Present and future commercial applications, Science, 2013, vol. 339, no. 6119 , pp. $535-539$.

https://doi.org/10.1126/science.1222453

38. Finn, R.D., Bateman, A., Clements, J., Coggill, P., Eberhardt, R.Y., and Eddy, S.R., Pfam: The protein families database, Nucleic Acids Res., 2014, vol. 42, no. D1, pp. D222-D230. https://doi.org/10.1093/nar/gkt1223

39. Raposo, G. and Stoorvogel, W., Extracellular vesicles: Exosomes, microvesicles, and friends, J. Cell Biol., 2013, vol. 200, no. 4, pp. 373-383. https://doi.org/10.1083/jcb.201211138

40. Mei, J., Leung, N.L.C., Kwok, R.T.K., Lam, J.W.Y., and Tang, B.Z., Aggregation-induced emission: Together we shine, united we soar!, Chem. Rev., 2015, vol. 115, no. 21, pp. 11718-11940. https://doi.org/10.1021/acs.chemrev.5b00263

41. Roffi, M., Patrono, C., Collet, J.-P., et al., 2015 ESC Guidelines for the management of acute coronary syndromes in patients presenting without persistent STsegment elevation: Task force for the management of acute coronary syndromes in patients presenting without persistent ST-segment elevation of the European Society of Cardiology (ESC), Eur. Heart J., 2016, vol. 37 , no. 3 , pp. $267-315$.

https://doi.org/10.1093/eurheartj/ehv320

42. Arber, D.A., Orazi, A., Hasserjian, R., et al., The 2016 revision to the World Health Organization classification of myeloid neoplasms and acute, Leukemia Blood, 2016, vol. 127 , no. 20 , pp. 2391-2405.

https://doi.org/10.1182/blood-2016-03-643544

43. Yabuuchi, N., Kubota, K., Dahbi, M., and Komaba, S., Research development on sodium-ion batteries, Chem. Rev., 2014, vol. 114, no. 23, pp. 11636-11682. https://doi.org/10.1021/cr500192f

44. Shamseer, L., Moher, D., Clarke, M., et al., Preferred reporting items for systematic review and meta-analysis protocols (PRISMA-P) 2015: Elaboration and explanation, BMJ (Online), 2015, vol. 349, p. g7647. https://doi.org/10.1136/bmj.g7647

45. Black, R.E., Victora, C.G., Walker, S.P., et al., Maternal and child undernutrition and overweight in low-income and middle-income countries, Lancet, 2013, vol. 382 , no. 9890 , pp. $427-451$. https://doi.org/10.1016/S0140-6736(13)60937-X

46. Butler, S.Z., Hollen, S.M., Cao, L., et al., Progress, challenges, and opportunities in two-dimensional materials beyond graphene, ACS Nano, 2013, vol. 7, no. 4, pp. 2898-2926.

https://doi.org/10.1021/nn400280c
47. Klionsky, D., J., Abdelmohsen, K., Abe, A., et al., Guidelines for the use and interpretation of assays for monitoring autophagy (3rd edition), Autophagy, 2016, vol. 12 , no. 1 , pp. $1-222$.

https://doi.org/10.1080/15548627.2015.1100356

48. Standards of Medical Care in Diabetes - 2013, Diabetes Care, 2013, vol. 36, suppl. 1, pp. S11-S66.

https://doi.org/10.2337/dc13-S011

49. Simon, P., Gogotsi, Y., and Dunn, B., Where do batteries end and supercapacitors begin?, Science, 2014, vol. 343 , no. 6176 , pp. $1210-1211$.

https://doi.org/10.1126/science.1249625

50. Larcher, D. and Tarascon, J.-M., Towards greener and more sustainable batteries for electrical energy storage, Nat. Chem., 2015, vol. 7, no. 1, pp. 19-29.

https://doi.org/10.1038/nchem.2085

51. Piepoli, M.F., Hoes, A.W., Agewall, S., et al., 2016 European Guidelines on cardiovascular disease prevention in clinical practice, Eur. Heart J., 2016, vol. 37, no. 29 , pp. $2315-2381$.

https://doi.org/10.1093/eurheartj/ehw106

52. Xu, M., Liang, T., Shi, M., and Chen, H., Graphenelike two-dimensional materials, Chem. Rev., 2013, vol. 113 , no. 5 , pp. 3766-3798.

https://doi.org/10.1021/cr300263a

53. Hu, Z., Deibert, B.J., and Li, J., Luminescent metalorganic frameworks for chemical sensing and explosive detection, Chem. Soc. Rev., 2014, vol. 43, no. 16, pp. $5815-5840$.

https://doi.org/10.1039/c4cs00010b

54. Stone, N.J., Robinson, J.G., Lichtenstein, A.H., et al., 2013 ACC/AHA guideline on the treatment of blood cholesterol to reduce atherosclerotic cardiovascular risk in adults: A report of the American College of Cardiology/American Heart Association Task Force on practice guidelines, Circulation, 2014, vol. 129, no. 2, suppl. 1, pp. S1-S45. https://doi.org/10.1161/01.cir.0000437738.63853.7a

55. Yu, N. and Capasso, F., Flat optics with designer metasurfaces, Nat. Mater., 2014, vol. 13, no. 2, pp. 139-150. https://doi.org/10.1038/nmat3839

56. Schneider, J., Matsuoka, M., Takeuchi, M., et al., Understanding $\mathrm{TiO}_{2}$ photocatalysis, Mech. Mater. Chem. Rev., 2014, vol. 114, no. 19, pp. 9919-9986.

https://doi.org/10.1021/cr5001892

57. Hsu, P.D., Lander, E.S., and Zhang, F., Development and applications of CRISPR-Cas9 for genome engineering, Cell, 2014, vol. 157, no. 6, pp. 1262-1278. https://doi.org/10.1016/j.cell.2014.05.010

58. Mikhailov, O.V., Tsitirovanie i tsitiruemost'v nauke: $\mathrm{Ob}$ shchie printsipy tsitirovaniya. Sovremennye kolichestvennye pokazateli tsitiruemosti. Tsitiruemost' $i$ kachestvo nauchnoi deyatel'nosti issledovatelya (Citing and Citation in Science: General Principles of Citation. Modern Quantitative Indicators of Citation. Citation and Quality of Researcher's Scientific Activity), Moscow: LENAND, 2017.

59. Larivière, V., et al., The place of serials in referencing practices: Comparing natural sciences and engineering with social sciences and humanities, J. Am. Soc. Inf. Sci. Technol., 2006, vol. 57, no. 8, pp. 997-1004. 
60. Liu, W., et al., The effect of publishing a highly cited paper on journal's impact factor: A case study of the Review of Particle Physics, arXiv Preprints, 2017. arXiv: 1712.03666 .

61. Meek, S.T., Greathouse, J.A., and Allendorf, M.D., Metal-organic frameworks: Metal-organic frameworks: A rapidly growing class of versatile nanoporous materials, Adv. Mater., 2011, vol. 23, no. 2, pp. 249267.

62. Rodríguez-Navarro, A., Measuring research excellence: Number of Nobel Prize achievements versus conventional bibliometric indicators, J. Doc., 2011, vol. 67 , no. 4 , pp. 582-600. https://doi.org/10.1108/00220411111145007

63. Guo, Q., et al., Single molecule photocatalysis on $\mathrm{TiO}_{2}$ surfaces: Focus review, Chem. Rev., 2019, vol. 119, no. 20, pp. 11020-11041.

64. Kalimullin, L.V., Levchenko, D.K., Smirnova, Yu.B., and Tuzikova, E.S., Priority directions, key technologies, and scenarios for the development of energy storage systems, Vestn. ISEU, 2019, no. 1. https://cyberleninka.ru/article/n/prioritetnye-napravleniya-klyuchevye-tehnologii-i-stsenarii-razvitiya-sistemnakopleniya-energii. Cited October 13, 2020.

65. Bhardwaj, P., Sinha, S., and Yadav, R.K., Medical and scientific writing: Time to go lean and mean, Perspect. Clin. Res., 2017, vol. 8, no. 3, pp. 113.

66. Puzin, S.N., Shurgaya, M.A., Bogova, O.T., et al., Medical and social aspects of population health. Modern approaches to the prevention of socially significant diseases, Med.-Sots. Ekspertiza Reab., 2013, no. 3, pp. 3-10.
67. 10 Leading Causes of Death in the World, World Health Organization. https://www.who.int/ru/newsroom/fact-sheets/detail/the-top-10-causes-of-death. Cited September 12, 2020.

68. Picknett, T. and Davis, K., The 100 most-cited articles from JMB, J. Mol. Biol., 1999, vol. 293, no. 2, pp. 173176.

69. Adele Diamond. http://www.devcogneuro.com/AdeleDiamond.html. Cited July 2020.

70. Mareev, V.Y., et al., Russian Heart Failure Society, Russian Society of Cardiology. Russian Scientific Medical Society of Internal Medicine Guidelines for Heart Failure: Chronic (CHF) and acute decompensated (ADHF). Diagnosis, prevention, and treatment, Kardiologiya, 2018, vol. 58, no. 6, pp. 8-158.

71. Mzhel'skii, A.A. and Moskaleva, O.V., Scientific cooperation as a factor affecting the citation of an article. Analytical review, Upr. Naukoi: Teor. Prakt., 2020, vol. 2, no. 3, pp. 138-164.

72. Lukina, Yu.V., Martsevich, S.Yu., and Kutishenko, N.P., Systematic review and meta-analysis: Pitfalls of methods, Ratsion. Farmakoter. Kardiol., 2016, vol. 12, no. 2, pp. $180-185$.

73. Ho, Y.S. and Kahn, M., A bibliometric study of highly cited reviews in the Science Citation Index expanded ${ }^{\mathrm{TM}}$, J. Assoc. Inf. Sci. Technol., 2014, vol. 65, no. 2, pp. 372385.

https://doi.org/10.1002/asi.22974

74. Garfield, E. and Welljamsdorof, A., Of Nobel class: A citation perspective on high-impact research authors, Theor. Med. Bioethics, 1992, vol. 13, no. 2, pp. 117-135.

Translated by S. Avodkova 